\title{
Incidence and risk factors of ventilator associated pneumonia in a tertiary care
}

\section{hospital}

MV Pravin Charles ${ }^{1}$, Joshy M Easow ${ }^{1}$, Noyal M Joseph ${ }^{1}$, M Ravishankar², Shailesh Kumar ${ }^{1}$, Sivaraman

\author{
Umadevi ${ }^{1}$
}

1. Department of Microbiology and 2. Department of Anaesthesiology

Mahatma Gandhi Medical College and Research Institute, Pondicherry, India

\section{RESEARCH}

Please cite this paper as: Charles MVP, Joshy M Easow, Joseph NM, Ravishankar M, Kumar S, Umadevi S. Incidence and risk factors of ventilator associated pneumonia in a tertiary care hospital. AMJ 2013, 6, 4, 178-182. http://doi.org/10.21767/AMJ.2013.1627

\section{Corresponding Author:}

Dr. MV Pravin Charles,

Assistant Professor,

Department of Microbiology,

Mahatma Gandhi Medical College and Research Institute, Pillaiyarkuppam, Pondicherry - 607402 (India).

Email: dr mvpravincharles@yahoo.com

\section{Abstract}

\section{Background}

Ventilator associated pneumonia (VAP) is a type of nosocomial pneumonia associated with increased morbidity and mortality. Knowledge about the incidence and risk factors is necessary to implement preventive measures to reduce mortality in these patients.

\section{Method}

A prospective study was conducted at a tertiary care teaching hospital for a period of 20 months from November 2009 to July 2011. Patients who were on mechanical ventilation (MV) for more than 48 hours were monitored at frequent intervals for development of VAP using clinical and microbiological criteria until discharge or death.

Results

Of the 76 patients, 18 (23.7\%) developed VAP during their ICU stay. The incidence of VAP was 53.25 per 1,000 ventilator days. About $94 \%$ of VAP cases occurred within the first week of MV. Early-onset and late-onset VAP was observed in $72.2 \%$ and $27.8 \%$, respectively. Univariate analysis showed chronic lung failure, $\mathrm{H}_{2}$ blockers usage, and supine head position were significant risk factors for VAP. Logistic regression revealed supine head position as an independent risk factor for VAP.

\section{Conclusion}

VAP occurred in a sizeable number of patients on MV. Chronic lung failure, $\mathrm{H}_{2}$ blockers usage, and supine head position were the risk factors associated with VAP. Awareness about these risk factors can be used to inform simple and effective preventive measures.

Key Words

VAP; incidence; risk factors

\section{Background}

Ventilator associated pneumonia (VAP) is a type of nosocomial pneumonia which occurs in patients who receive mechanical ventilation $(\mathrm{MV})$ via tracheal or tracheostomy tube. ${ }^{1}$ Differences in VAP incidences have been based on the antibiotic profile, ICU environment, and the population of study. ${ }^{2}$ According to The National Nosocomial Infection Surveillance Program the incidence of VAP is 7.6 cases per 1000 patient ventilator days. ${ }^{3}$ The incidence of VAP ranges from $28-32 \% .{ }^{4,5}$ This difference is a result of the diversity of diagnostic methods used. Development of VAP $\leq 96$ hours of MV is classified as early onset; a delay of more than 96 hours is termed as late onset. ${ }^{6}$ Intubation alone is a risk factor for the development of pneumonia among hospitalised patients. ${ }^{7}$ Both the host and intervention associated risk factors increase the mortality among these patients. ${ }^{1}$ The end result is either colonisation or aspiration of the respiratory contents with potential pathogens. ${ }^{8,9}$ The mortality rate among these patients ranges from $16-20 \% .{ }^{6,10}$ A study of both incidence and risk factors was necessary to implement preventive measures and thereby reduce mortality rate in these patients.

\section{Method}

\section{Study design}

A prospective study was conducted at a tertiary care teaching hospital over a period of 20 months from November 2009 to July 2011. 
All patients admitted in the ICU who received MV were included in the study. Patients who were mechanically ventilated for less than 48 hours and those who had developed pneumonia prior to initiation of $\mathrm{MV}$ were excluded from the study. The study was approved by the institute ethics committee. Informed consent was obtained from the patient's next of kin.

Figure 1: Flowchart showing the inclusion and exclusion of patients

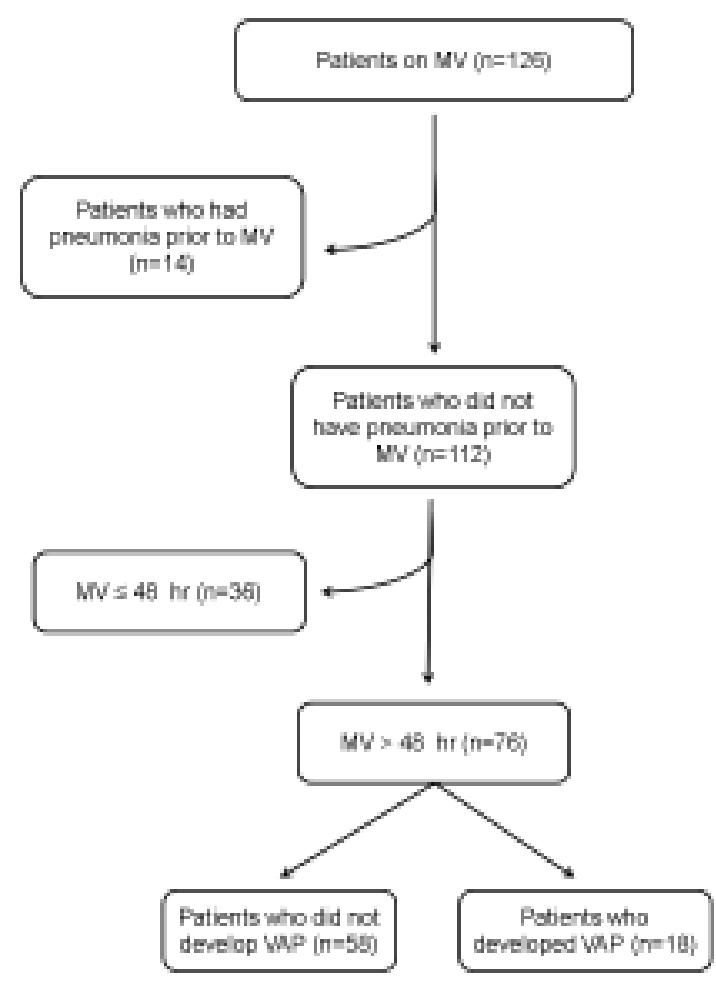

\section{Data collection}

The following variables were collected: age, sex, provisional diagnosis, date of hospital admission, and duration of MV. The patients included in this study were monitored at frequent intervals (every 48 hours) for the development of VAP using clinical and microbiological criteria till discharge or death. The parameters such as fever, chest X-ray, oxygenation, leukocytosis, and other risk factors were collected every 48 hours.

\section{Microbiological methods}

EA was serially diluted in sterile normal saline as $1 / 10$, $1 / 100,1 / 1000$ and $0.01 \mathrm{ml}$ of $1 / 1000$ dilution was inoculated on $5 \%$ sheep blood agar. After incubation at $37^{\circ} \mathrm{C}$ in $5 \% \mathrm{CO}_{2}$ incubator for 24 hours, colony count was completed and expressed as number of colony forming units per $\mathrm{ml}(\mathrm{CFU} / \mathrm{ml})$. The number of $\mathrm{CFU} / \mathrm{ml}$ is equal to number of colonies on agar plate $x$ dilution factor $x$ inoculation factor. Therefore, the presence of a single colony on the blood agar after inoculating $0.01 \mathrm{ml}$ of 1 /
1000 times diluted EA was interpreted as more than $10^{5}$ CFU/ ml. ${ }^{11}$ The isolates were identified based on standard bacteriological techniques. ${ }^{12}$

\section{Diagnosis}

VAP was diagnosed in patients who fulfilled both clinical and microbiological criteria. A clinical diagnosis was made with the use of the modified Clinical Pulmonary Infection Score (CPIS) based on six clinical assessments, each worth zero to two points. ${ }^{13}$ VAP was confirmed microbiologically in patients with quantitative endotracheal aspirate culture indicative of $\geq 10^{5} \mathrm{CFU} / \mathrm{ml}$ with a positive Gram stain (>10 Polymorphonuclear cells/ high power field and $\geq 1$ bacteria/ oil immersion field). ${ }^{14-16}$

\section{Method of analysis}

Results were expressed as mean \pm SD. Continuous variables were compared using Student's $t$ test for normally distributed variables. Univariate analysis with chi-square or Fisher's exact test was performed to compare the risk factors in patients with and without VAP. Univariate results were confirmed with logistic regression analysis using statistics software (SPSS 16.0, SPSS Inc, Chicago, Illinois). This was necessary to avoid producing spuriously significant results with multiple comparisons. A stepwise approach was used to enter new terms into the model with 0.05 as the limit for their acceptance or removal. Results of the logistic regression analyses were reported as estimated odd ratios with their $95 \%$ confidence intervals. All $p$ values $<0.05$ were considered statistically significant.

\section{Results}

During a 20-month period (November 2009 to July 2011), 112 consecutive patients admitted to the ICU were prospectively evaluated. Of these, 36 (32.1\%) were excluded due to mechanical ventilation for less than 48 hours. The remaining 76 (67.9\%) patients who received MV for $>48 \mathrm{~h}$ were studied.

Of the 76 patients, 18 (23.7\%) developed VAP during their ICU stay. Early onset VAP occurred in 13 (72.2\%), while late onset VAP was observed in the remaining 5 (27.8\%) patients. Ninety-four per cent (17 out of 18) of VAP cases occurred within the first week of MV. The incidence of VAP was 53.25 per 1,000 ventilator day.

Of the 76 study patients, 56 were men (73.7\%) and 20 $(26.3 \%)$ were women. The mean \pm SD age of patients receiving $M V$ was $48.11 \pm 18.2$ years (range, 14 to 82 years). The comparison of the age and sex distribution of the patients with and without VAP is shown in Table 1 . The most frequent cause of ICU admission was poisoning 
(22.4\%). There was no statistically significant difference in the distribution of the various primary illnesses in the patients with and without VAP (Table 2).

Table 1: Age and sex distribution of the patients with and without VAP

\begin{tabular}{llll}
\hline Parameter & $\begin{array}{l}\text { Non-VAP } \\
(\mathbf{n}=\mathbf{5 8})\end{array}$ & VAP $(\mathbf{n}=\mathbf{1 8})$ & $\begin{array}{l}\mathbf{P} \text { value } \\
\text { (2-tailed) }\end{array}$ \\
\hline $\begin{array}{l}\text { Age (mean } \pm \text { SD) } \\
\text { Gender }\end{array}$ & $48.2 \pm 18.4$ & $47.8 \pm 17.8$ & 0.94 \\
$\quad$ Male & $41(70.7 \%)$ & $15(83.3 \%)$ & 0.36 \\
$\quad$ Female & $17(23.3 \%)$ & $03(16.7 \%)$ & \\
\hline
\end{tabular}

Table 2: Primary diagnosis of the study patients

\begin{tabular}{llll}
\hline Primary diagnosis & $\begin{array}{l}\text { Non-VAP } \\
\text { (n= 58) }\end{array}$ & $\begin{array}{l}\text { VAP } \\
\text { (n= 18) }\end{array}$ & P value \\
\hline Cardiovascular disease & $9(15.5)$ & $4(22.2)$ & 0.49 \\
CNS infections & $4(6.9)$ & $1(5.6)$ & 1.00 \\
Intra-abdominal & $8(13.8)$ & $4(22.2)$ & 0.46 \\
diseases & & & \\
Neurological disorders & $6(10.3)$ & - & \\
Poisoning & $13(22.4)$ & $4(22.2)$ & 1.00 \\
Respiratory disease & $12(20.7)$ & $4(22.2)$ & 1.00 \\
Trauma & $1(1.7)$ & $1(5.6)$ & 0.42 \\
Other & $5(8.6)$ & - & \\
\hline
\end{tabular}

Pseudomonas aeruginosa (33.3\%) was the most common organism isolated from VAP patients. It was followed by Klebsiella pneumoniae (20.8\%), Staphylococcus aureus (8.3\%), Candida albicans (8.3\%), Escherichia coli (8.3\%), Acinetobacter baumannii (4.2\%) and Stenotrophomonas maltophilia (4.2\%).
Univariate analysis indicated that chronic lung failure, use of $\mathrm{H}_{2}$ blockers, and supine head position were significantly associated with VAP (Table 3). Selected risk factors were entered into a logistic regression model to perform the multivariate analysis which revealed that supine head position was an independent risk factor for VAP (Table 4).

Table 4: Logistic regression analysis of the risk factors for VAP

\begin{tabular}{lllll}
\hline & $\begin{array}{l}\text { Estimated } \\
\text { Odds ratio }\end{array}$ & P value & \multicolumn{2}{c}{$\begin{array}{l}\text { 95\% } \\
\text { interval }\end{array}$} \\
\cline { 3 - 5 } & & & confidence \\
& & 0.07 & 0.85 & 44.12 \\
\hline $\begin{array}{l}\text { Chronic lung } \\
\text { failure }\end{array}$ & 6.12 & & & \\
$\mathrm{H}_{2}$ blockers & 4.42 & 0.07 & 0.87 & 22.40 \\
$\begin{array}{l}\text { Supine head } \\
\text { position }\end{array}$ & 5.00 & 0.02 & 1.17 & 21.24 \\
\hline
\end{tabular}

\section{Discussion}

Ventilator associated pneumonia is a type of nosocomial infection acquired in the ICU. We observed that the incidence of VAP was about $23.7 \%$, which is comparable to the observations made in several other studies. In a study conducted from four multidisciplinary intensive care units from Greece the incidence was reported to be $32 \% .{ }^{4}$ In a evaluation made in Boston, VAP was reported at the rate of 10.2\% per 1000 ventilator days. ${ }^{17}$ Similarly Gupta A and coworkers, reported an incidence of $28.0 \% .{ }^{5}$ In a study from South India the incidence was reported to be $18 \%{ }^{6}$

Table 3: Univariate analysis of the risk factors for VAP

\begin{tabular}{|c|c|c|c|c|}
\hline Risk factor & $\begin{array}{l}\text { Non-VAP } \\
(n=58)(\%)\end{array}$ & $\begin{array}{l}\text { VAP } \\
(n=18)(\%)\end{array}$ & $\begin{array}{l}\text { Relative risk (95\% confidence } \\
\text { limits) }\end{array}$ & P value \\
\hline Chronic lung failure & $2(3.4)$ & $4(22.2)$ & 3.33 (1.60 to 6.95$)$ & 0.0255 \\
\hline $\mathrm{H}_{2}$ blockers & $34(58.6)$ & $16(88.8)$ & $4.16(1.03$ to 16.73$)$ & 0.0375 \\
\hline Supine head position & $30(51.7)$ & $15(83.3)$ & 3.44 (1.09 to 10.90$)$ & 0.0349 \\
\hline Age $\geq 60$ yrs & $14(24.1)$ & $3(16.7)$ & 0.69 (0.23 to 2.12$)$ & 0.7473 \\
\hline Organ failure & $4(6.9)$ & $3(16.7)$ & $1.97(0.75$ to 5.18$)$ & 0.3461 \\
\hline Abdomino-thoracic surgery & $10(17.2)$ & $2(11.1)$ & 0.67 (0.18 to 2.53$)$ & 0.7199 \\
\hline ARDS & $5(8.6)$ & $2(11.1)$ & $1.23(0.35$ to 4.29$)$ & 0.6667 \\
\hline Impaired consciousness & $20(34.5)$ & $6(33.3)$ & 0.96 (0.41 to 2.27$)$ & 0.8457 \\
\hline Tracheostomy & $2(3.4)$ & $1(5.5)$ & $1.43(0.27$ to 7.48$)$ & 0.5611 \\
\hline Nasogastric tube & $49(84.5)$ & $15(83.3)$ & 0.94 (0.32 to 2.75$)$ & 1.0000 \\
\hline Steroids & $5(8.6)$ & $1(5.5)$ & $0.69(0.11$ to 4.31$)$ & 1.0000 \\
\hline Emergency intubation & $7(12.1)$ & $1(5.5)$ & 0.50 (0.08 to 3.27$)$ & 0.6716 \\
\hline
\end{tabular}


VAP is generally classified as early onset and late onset based on the time of onset of VAP. In our study, early onset VAP occurred in $13(72.2 \%)$ patients, while late onset VAP was observed in the remaining 5 (27.8\%) individuals. Other studies have reported early-onset VAP in almost half of all VAP episodes. ${ }^{18,19}$

We observed that about $94 \%$ (17 out of 18) of VAP cases occurred within the first week of mechanical ventilation. Apostolopoulou et al also had documented that there was an increased risk of developing VAP during the first two weeks of MV. The increased risk is mainly attributed to the interaction of several risk factors during the initial days of MV.

The patients who developed VAP in the present study were admitted for various clinical disorders. There was no significant association between the occurrence of VAP and the primary diagnosis of the patients, however the small number of patients in our study group could have resulted in our failure to find significant associations in our subgroups. For example, in a similar study from South India, patients with neurological disorders and CNS infections were observed to be significantly predisposed for the development of VAP. ${ }^{6}$ In other studies intra-abdominal diseases and multiple injury were noted to be significant predisposing factors for VAP. ${ }^{2,4,18}$

Risk factors for the development of VAP were evaluated in the present study. The host and intervention factors such as, age $\geq 60$ years, organ failure, abdominal or thoracic surgery, ARDS, chronic lung failure, impaired consciousness, tracheostomy, nasogastric tube, $\mathrm{H}_{2}$ blockers, supine head position, steroids usage, and emergency intubation were evaluated. We observed chronic lung failure, $\mathrm{H}_{2}$ blockers usage, and supine head position were significantly associated with VAP by univariate analysis, while supine head position was found to be the only independent risk factor for VAP by logistic regression. The defective lung function along with the pre-existing lung damage in patients with chronic lung failure may be responsible for the increased occurrence of VAP in these patients. Similarly, $\mathrm{H}_{2}$ blockers usage was associated with an increased risk as it can alter the gastric $\mathrm{pH}$ thereby facilitating organism multiplication which, when aspirated, can lead to occurrence of VAP. Supine head position increases the risk of aspiration of the gastric contents and could explain some of the increase in the rate of VAP in critically ill patients. Awareness of these risk factors can aid in identification of patients at higher risk, guide institution of appropriate preventive measures, and modulate potential intervention measures while managing such patients. Supine head position, stress ulcer prophylaxis, surgery, burns, chronic renal failure, trauma, steroid therapy and duration of $M V \geq$ $5 \mathrm{~d}$ were documented as risk factors in other studies. ${ }^{2,18}$ In another study, impaired consciousness, tracheostomy, reintubation, emergency intubation, and nasogastric tube were found to be independent risk factors for VAP. ${ }^{6}$ Awareness of these risk factors helps to overcome the adverse effects of VAP.

\section{Conclusion}

VAP, an important nosocomial infection among the critically ill patients, requires purposeful study to reduce mortality. Good knowledge of VAP and its associated parameters is important. Despite the small sample size which is a limitation of our study, our findings emphasize the importance of the several risk factors for VAP. Further studies on incidence and risk factors can facilitate knowledge translation activities about the disease and thereby minimise the occurrence of VAP through the implemention of simple, low cost preventive measures. Awareness about the various risk factors will aid in reduction of the morbidity and mortality associated with VAP.

\section{References}

1. Alp E, Voss A. Ventilator associated pneumonia and infection control. Ann Clin Microbiol Antimicrob. 2006 Apr 6;5:7.

2.Niederman MS, Craven DE. Guidelines for the management of adults with hospital-acquired, ventilatorassociated, and healthcare-associated pneumonia. Am J Respir Crit Care Med 2005;171:388-416.

3. Edwards JR, Peterson KD, Andrus ML, Tolson JS, Goulding JS, Dudeck MA, Mincey RB, Pollock DA, Horan TC; NHSN Facilities. National Healthcare Safety Network (NHSN) Report, data summary for 2006, issued June 2007. Am J Infect Control 2007;35:290-301.

4. Apostolopoulou E, Bakakos P, Katostaras T, Gregorakos L. Incidence and risk factors for ventilator-associated pneumonia in 4 multidisciplinary intensive care units in Athens, Greece. Respir Care. 2003;48:681-8.

5. Gupta A, Agrawal A, Mehrotra S, Singh A, Malik S, Khanna A. Incidence, risk stratification, antibiogram of pathogens isolated and clinical outcome of ventilator associated pneumonia. Indian J Crit Care Med 2011;15:96-101.

6. Joseph NM, Sistla S, Dutta TK, Badhe AS, Parija SC. Ventilator-associated pneumonia in a tertiary care hospital in India: incidence and risk factors. J Infect Dev Ctries 2009;3:771-7.

7. Rello J, Diaz E. Pneumonia in the intensive care unit. Crit Care Med 2003;31:2544-51. 
8. Erbay RH, Yalcin AN, Zencir M, Serin S, Atalay H. Costs and risk factors for ventilator-associated pneumonia in a Turkish university hospital's intensive care unit: a case-control study. BMC Pulm Med 2004;4:3.

9. Safdar N, Crnich CJ, Maki DG. The pathogenesis of ventilator-associated pneumonia: its relevance to developing effective strategies for prevention. Respir Care 2005;50:725-39.

10. Heyland DK, Cook DJ, Griffith L, Keenan SP, Brun-Buisson C. The attributable morbidity and mortality of ventilatorassociated pneumonia in the critically ill patient. The Canadian Critical Trials Group. Am J Respir Crit Care Med 1999;159:1249-56.

11. Baselski VS, el-Torky M, Coalson JJ, Griffin JP. The standardization of criteria for processing and interpreting laboratory specimens in patients with suspected ventilatorassociated pneumonia. Chest 1992;102:571S-9S.

12. Mackie TJ, McCartney JE. Practical medical microbiology. 14th ed. New York: Churchill Livingstone; 1996.

13. Pugin J, Auckenthaler R, Mili N, Janssens JP, Lew PD, Suter PM. Diagnosis of ventilator-associated pneumonia by bacteriologic analysis of bronchoscopic and nonbronchoscopic "blind" bronchoalveolar lavage fluid. Am Rev Respir Dis 1991;143:1121-9.

14. Koenig SM, Truwit JD. Ventilator-associated pneumonia: diagnosis, treatment, and prevention. Clin Microbiol Rev 2006;19:637-57.

15. Porzecanski I, Bowton DL. Diagnosis and treatment of ventilator-associated pneumonia. Chest 2006;130:597-604.

16. Wu CL, Yang DI, Wang NY, Kuo HT, Chen PZ. Quantitative culture of endotracheal aspirates in the diagnosis of ventilator-associated pneumonia in patients with treatment failure. Chest 2002;122:662-8.

17. Bird D, Zambuto A, O'Donnell C, Silva J, Korn C, Burke R, Burke $\mathrm{P}$, Agarwal $\mathrm{S}$. Adherence to ventilator-associated pneumonia bundle and incidence of ventilator-associated pneumonia in the surgical intensive care unit. Arch Surg 2010;145:465-70.

18. Chastre J, Fagon JY. Ventilator-associated pneumonia. Am J Respir Crit Care Med 2002;165:867-903.

19. Kollef $\mathrm{MH}$. What is ventilator-associated pneumonia and why is it important? Respir Care 2005;50:714-21.

20. Joseph NM, Sistla S, Dutta TK, Badhe AS, Parija SC. Ventilator-associated pneumonia in a tertiary care hospital in India: incidence and risk factors. J Infect Dev Ctries 2009;3:771-7. 